\title{
Evolução dos Conhecimentos sobre Vetores da Doença de Chagas 90 Anos após sua Descoberta
}

\author{
Herman Lent \\ Departamento de Ciências Biológicas, Instituto de Ciências Biológicas e Ambientais, Universidade Santa \\ Úrsula, Rua Fernando Ferrari 75, 22231-040 Rio de Janeiro, RJ, Brasil
}

Key words: doença de Chagas - vetores - Trypanosoma - Triatoma

Quando se solicita a um entomologista algo que possa lembrar o nonagésimo aniversário da descoberta da doença de Chagas e esse entomologista não viveu a época do fato importante, só resta pesquisar. E como pesquisar foi e vem sendo todo objetivo de minha carreira científica, aí vai o que achei conveniente falar.

A época se enquadra nos últimos anos do século XIX e os primeiros do século XX, quando a peste bacteriana, a malária, a febre amarela e a varíola eram os grandes problemas de saúde pública. O surto de peste bubônica na zona portuária de Santos, SP, levou Oswaldo Gonçalves Cruz a envolver-se com a profilaxia da doença transmitida pelas pulgas (Xenopsylla chaeopis principalmente) que infestavam os ratos que chegavam do exterior através de navios ancorados no porto.

Foi a primeira missão conhecida do Instituto Soroterápico Federal, atribuída a Oswaldo Cruz para auxiliar o combate à doença que também preocupava o Instituto Bacteriológico de São Paulo, onde aparecia a figura notável de Adolpho Lutz, posteriormente transferido para Manguinhos onde já se formava o primeiro grupo de entomologistas.

Apesar das preocupações do combate às epidemias, Oswaldo Cruz e Carlos Chagas foram os primeiros, em Manguinhos, a estudar e publicar trabalhos sobre insetos, fatos pouco divulgados com algum relevo.

Ainda com as preocupações ligadas à profilaxia contra o mosquito, então conhecido como "estegomia", Oswaldo Cruz foi solicitado a cuidar da malária que estava impedindo a progressão dos trabalhos de construção da Estrada de Ferro Central do Brasil.

Carlos Chagas foi designado para o trabalho clínico-profilático na ponta dos trilhos da estrada e se instalou na localidade de Lassance, MG. Aí,

Conferência proferida em 15 de abril de 1999.

Recebido em 9 de junho de 1999

Aceito em 9 de agosto de 1999 em suas observações nos doentes encontrava sintomas de malária, mas também outros diferentes dos característicos da epidemia ali reinante. Assim permaneceu quase um ano com suas suspeitas, até que examinando pequenos macacos comuns na região, encontrou um protozoário que considerou nova espécie: era um Trypanosoma.

Concomitantemente, lhe foi trazido por um colega - Dr. Fernando Soledade - e confirmado pelos habitantes das cafuas, residências das populações, um grande inseto que chupava sangue do homem, era hematófago assim como o percevejo de cama, e que chamavam pelo nome de "percevejão". Examinado o inseto logo identificado como de gênero Conorrhinus, encontrou outro protozoário Trypanosoma no intestino do novo hematófago. Em contato frequiente com Oswaldo Cruz publicou seu primeiro trabalho em alemão, em importante revista de Leipzig, descrevendo sob perfeita nomemclatura zoológica as espécies Trypanosoma minasense $\mathrm{n}$. sp. e Trypanosoma cruzi n. sp. Diferenciou as duas espécies e logo associou a existência do inseto hematófago nas habitações humanas com os sintomas observados, assim caracterizando uma nova doença do homem - a tripanosomíase americana - que mais tarde recebeu o nome de doença de Chagas.

Daí em diante, voltando a Manguinhos e publicando a nota prévia em português e em outros idiomas incluiu ampliações que caracterizavam a doença, a causa e o vector. Este último foi identificado corretamente como Triatoma megista (Burmeister, 1835) sendo estudado em laboratório seu ciclo biológico por Arthur Neiva que assim se associa a Oswaldo Cruz e Carlos Chagas como os primeiros a criar em laboratório o inseto obtido na natureza.

Enquanto se estabeleciam os primeiros comentários, elogiosos uns, críticos outros, principalmente na Academia Nacional de Medicina, envolvendo os nomes dos maiores clínicos da época e Oswaldo Cruz preocupado com a campanha da vacinação anti-variólica apareciam as primeiras grandes teses entomológicas como a de Peryassu em 1908 sobre mosquitos, a de Rohr em 1909 so- 
bre Ixodídeos, a de Almeida Cunha (1914) sobre pulgas e a de Neiva (1914) sobre triatomíneos.

Como decorrência do estabelecimento da espécie que se infectava com o T. cruzi, o primeiro hemiptero conhecido como vector de doença no homem, Neiva passou a dedicar-se a seu estudo e publicou várias espécies novas que se reuniram em sua tese de Livre Docência de 1914.

Chagas em seu primeiro trabalho tratou a espécie vectora como do gênero Conorrhinus sp.? e logo depois como Conorhinus sanguisuga por sinal nome científico de espécie norte-americana que não ocorre no Brasil. Mas ainda em 1909 Chagas publica uma nítida estampa colorida do que em 1910, após o estudo de Neiva, veio a conhecer-se sob o nome de Conorhinus megistus Burmeister, 1835 , este exatamente o primeiro entomologista a publicar sobre o hematofagismo desse grande inseto até então desconhecido apesar de ter sido referido por vários viajantes que em expedições percorreram a América do Sul.

A estampa colorida e os demais desenhos de formas diversas do T. cruzi foram assinados por Castro Silva, o primeiro dos grandes desenhistas de Manguinhos.

Depois da tese de Neiva (1914) que reuniu o que na bibliografia existia sobre triatomíneos, começaram a surgir trabalhos de conjunto, como o de Cesar Pinto em 1925, o de Del Ponte em 1930 na Argentina também.

Já agora se considerava espécies que não viviam na habitação humana e procuravam o alimento em hospedeiros silvestres, mamíferos ou aves principalmente.

Em 1936 depois de iniciado o projeto de criação em laboratório e observação do ciclo de vida dos insetos, todos considerados como potenciais transmissores da doença de Chagas, divulgava-se o nome do primeiro entomólogo - De Geer, 1773, que deu origem ao gênero Triatoma com a espécie cosmopolita $-T$. rubrofasciata. A seguir, principalmente pela contribuição de Stal (1859) crescia o número de novas espécies e se estabeleciam outros gêneros.

Neiva e Lent em 1936 relacionaram 75 espécies distribuídas em 61 países em diversas regiões zoogeográficas. Logo em seguida ainda, Neiva e Lent, em 1941, listaram 89 nomes específicos para 63 países.

Poderemos avaliar o interesse despertado por esses insetos sabendo que numerosos nomes vulgares que eles receberam em vários países, muitos deles sugerindo a observação indígena de seus aspectos morfológicos e seus hábitos. Mesmo no Brasil, além de "barbeiro" poderemos citar "chupão", "chupança", "fincão", "furão", "bicudo", "percevejão", "bicho-de-parede", "bicho-de- parede-preto", "chupa-pinto", "percevejo-do-sertão", "percevejo-francês", "percevejo gaudério", "percevejo-grande", "procotó", "porocotó", "baratão", "bruxa", "cafote", "cascudo", "piolho de piaçava", "quiche do sertão", "rondão" e "vum-vum".

Além de "vinchuca" como na Argentina, Uruguai e Chile, é possível encontrar uma ampla e variada lista que entreguei para publicar no Livro de Lenko e Papavero, em segunda edição em 1996, Insetos no Folclore.

Com Usinger (1940) tivemos uma publicação restrita a Norte e Centro-América e com Abalos e Wygodzinsky (1951) um trabalho sobre espécies argentinas. E certo que a nomeclatura zoológica no decorrer do tempo veio se modificando, surgindo sinônimos de espécies então válidas e viceversa. A compreensão das estruturas observadas através da microscopia de varredura passou a definir melhor detalhes que a microscopia ótica permitiu.

Se, pulando no tempo chegarmos a 1979, a revisão de Lent e Wygodzinsky teve a oportunidade de, localizando o trabalho no importante American Museum of Natural History em Nova Iorque, receber para estudo exemplares preciosos que vinham por empréstimo e permitiam assim a comparação com o abundante material que conhecíamos. Foram estudadas e publicadas todas as espécies válidas de Triatominae distribuídas em tribos e gêneros, perfazendo um total de 110 espécies ilustradas ou fotografadas no total e nos detalhes importantes, com descrições detalhadas e referências sobre os ciclo de vida e habitats na natureza, além de chaves globais e outras regionais da distribuição por países, informações quanto à infestação pelo $T$. cruzi na natureza e no laboratório.

A obra facilitou o trabalho de pesquisadores, não somente entomólogos, como modelo para estudos em outras áreas afins, isto é morfometria, biologia molecular, genética e isoenzimas, que pretendem decidir sobre a validade de espécies taxonômicas ou complexos de espécies que não se definiam perfeitamente como válidas na visão dos próprios taxonomistas. Considero temerário dissertar sobre filogenia em subfamília da família Reduviidae onde existem 33 outras subfamílias. Pode parecer subjetivo.

Neste sentido tem importância fundamental o Laboratório Nacional e Internacional de Referência em Taxonomia de Triatomíneos localizado no Departamento de Entomologia do Instituto Oswaldo Cruz desde 1989 sob a direção de José Jurberg que mantém um banco de dados sobre os vetores, além da criação de um número considerável de espécies vivas.

É impossível em reunião bem organizada para comemorar o 90ㅡ aniversário da doença de Cha- 
gas ampliar mais do que o necessário sobre os insetos que a transmitem.

A mais recente publicação - Atlas dos Vetores da Doença de Chagas nas Américas - em três volumes, dois já publicados em 1998, cujo projeto inicial se deve principalmente a Rodolpho Carcavallo, trata o inseto como entidade taxonômica mas inclui diversos capítulos em áreas em que aparecem várias espécies como modelo.

A literatura é extensa e amplia constantemente este grupo de insetos que o hematofagismo tornou importante em relação ao parasitismo no homem.

\section{PRINCIPAIS REFERÊNCIAS BIBLIOGRÁFICAS} CITADAS NO TEXTO

\section{De Carlos Chagas}

Apud Coletânea de Trabalhos Científicos, 1981, Aluizio Prata, Univ. de Brasília.

1907 - Novas espécies de culicídeos brazileiros, 28 p., 3 figs (Trabalho do Inst. Manguinhos).

1907 - O novo gênero Myzorhynchella de Theobald. Duas novas anophelinas pertencentes a este gênero. Brasil-Méd 21(30): 291-293, (31): 303-305.

1907 - Uma espécie do gênero Taeniorhynchus. Brasil-Méd 21(32): 313-314, 3 figs.

1909 - Neue Trypanosomen. Vorläufige Mitteilung. Arch $f$ Schiffs-u Tropenhyg 13(4): 120-122 [fevereiro].

1909 - Nova espécie morbida do homem produzida por um Trypanosoma (T. cruzi). Nota prévia. Brasil-Méd 23(16): 161 [21 abril].

1909 - Nova trypanosomíase humana (Nota apresentada à Academia Nacional de Medicina). Gaz Méd Bahia 40(10): 433-440 [abril].

1909 - Uma nova trypanosomíase humana. Comunicação do Dr. Oswaldo Cruz à Academia Nacional de Medicina, em sessão de 22 de abril. Brasil-Méd 23(17): 175-176 [ $1^{\circ}$ maio].

1909 - Nova trypanosomíase humana. Imprensa méd 17(10): 154-155 [25 maio].

1909 - Nouvelle espèce de trypanosomiase humaine. Bull Soc Path Exot Paris 2(6): 304307 [ 9 junho].

1909 - Ueber eine neue trypanosomiasis des Menschen. Zweite vorläufige Mitteilung. Arch f Schiffs u Tropenhyg 13(11): 351-353, 2 figs.

1909 - Nova tripanosomiase humana. Estudos sobre a morfologia e o ciclo evolutivo do Schiizotrypanum cruzi n. gen., n.sp., agente etiológico de nova entidade mórbida do homem. Mem Inst Oswaldo Cruz 1(2): 159-218, figs. 1-10 no texto, est. 9-13 [agosto].

1911 - Nova entidade morbida do homem. Rezumo geral de estudos etiológicos e clínicos. Mem Inst Oswaldo Cruz 3(2): 219-275.

\section{De Oswaldo Cruz}

Apud Opera Omnia, 1972.

1901 - Contribuição para o estudo dos culicidios do Rio de Janeiro. Brasil-Méd 15(43): 423426, figs 1-7.

Descrição detalhada da forma adulta (fêmea), ovos e larvas. Deu o nome de Anopheles lutzii sem afirmar ser n. sp., comparou com $A$. albimanus Wied, A. albitarsis Arríbálzaga e A. argyrotarsis Desv.

1906 - Um novo gênero da sub-família "Anophelina”. Brasil-Méd 20(20): 199-200.

Descreve Chagasia nov. gen. e Chagasia neivae n.sp. - Diz que foi descrito com Neiva de exemplares trazidos por Chagas de Juiz de Fora.

1907 - Um novo gênero brazileiro da sub-familia “Anophelinae". Brasil-Méd 21(28): 271-273. Descreve Manguinhosia nov. gen.e Manguinhosia lutzi nov. sp. com muito detalhe. O material foi enviado por Chagas capturado à margem do Rio Bicudo, M.G. Comenta que o n. g. é próximo de Lophoscelomyia e Nyssorhynchus.

1907 - Uma nova espécie do gênero Psorophora. Brasil-Méd 21(34): 329-330.

Publica Psorophora genu-maculata nov. sp., fêmea com muito detalhe e o macho com menos detalhes. Diz que o material veio de Santos e deve aproximar-se de scintillans.

\section{Primeiras Teses Entomológicas}

1908 - Peryassú AG. Os Culicideos do Brazil. Trabalho do Instituto de Manguinhos, Rio de Janeiro, 407 pp., est., figs.

1909 - Rohr CJ. Estudos sobre Ixódidas do Brasil. Tese. Trabalho do Instituto Oswaldo Cruz, Rio de Janeiro, 220 pp., ests, bibliog.

1914 - Almeida Cunha R. Contribuição para o Estudo dos Siphonapteros do Brasil. Tese de Doutoramento, Mem Inst Oswaldo Cruz 6(2).

1914 - Neiva A. Revisão do gênero Triatoma Lap.. Tese de Livre Docência, 80 pp.

\section{Outras publicações citadas}

1925 - Pinto C. Ensaio Monográfico dos Reduviideos Hematófagos ou "Barbeiros". Tese, Fac. Med. Rio de Janeiro, 118 pp.

1930 - Del Ponte E. Catálogo descriptivo de los géneros Triatoma Lap., Rhodnius Stal e Eratyrus Stal. Rev Inst Bact, Buenos Aires, 5: 855-937.

1936 - Neiva A, Lent H. Notas e comentários sobre triatomideos. Lista de espéceis e sua distribuição geográfica. Rev Entom, Rio de Janeiro, 6 (2): 153-190.

1941 - Neiva A, Lent H. Sinopse dos tratomideos. 
Rev Entom, Rio de Janeiro, 12(1-2): 61-92.

1944 - Usinger R. The Triatominae of North and Central America and the West Indies. Public Health Bull 288: 83.

1951 - Abalos J, Wygodzinsky P. Las Triatominae Argentinas. Inst. Med. Regional, Tucumán, Monogr. 2, 179 pp.

1979 - Lent H, Wygodzinsky P. Revision of the Triatominae (Hemiptera, Reduviidae), and their significance as vectors of Chagas disease. Bull Amer Mus Nat Hist 163(3): 125-
520, figs $1-320$.

1996 - Jurberg J. A Taxonomia dos Triatomineos Baseada nas Estruturas Fálicas (Hemiptera, Reduviidae). Tese de Doutorado, UFRRJ, 60 pp.

1996 - Lenko K, Papavero N. Insetos no Folclore. Pléiade, São Paulo, 468 pp.

1998 - Carcavallo R, Gallindez Girón I, Jurberg J, Lent H. Atlas dos Vectores da Doença de Chagas nas Américas, Vol. 1 e 2, Fiocruz, Rio de Janeiro. 